\title{
Paz, territorio, Estado local y empresariado. Experiencias con el mecanismo de Obras por Impuestos en Risaralda*
}

Peace, Territory, Local State, and the Business Sector. Experiences with the Risaralda Public Works Tax Deduction Mechanism

Orlando Parra*

Fundación Universitaria Comfamiliar Risaralda, Colombia http://orcid.org/0000-0002-7890-809X

Artículo de investigación

Fecha de recepción: 4 de marzo de 2020

Fecha de aceptación: 17 de abril de 2020

\section{Para citar este artículo}

Parra, O. (2020). Paz, territorio, Estado local y empresariado. Experiencias con el mecanismo de Obras por Impuestos en Risaralda. Campos en Ciencias Sociales, 8(2), 263-290. DOI: https://doi.org/10.15332/25006681/6019

\footnotetext{
Este artículo es resultado de la investigación Identificar procesos usados por empresas de Risaralda para aportar a la construcción de la paz, que se desarrolló dentro de la línea de investigación Modelos de gerencia regional de la Fundación Universitaria Comfamiliar, y contó con el respaldo del semillero de investigación Paz + Empresas entre abril 4 y octubre 23 de 2019.

* Magíster en Historia; docente investigador de la Fundación Universitaria Comfamiliar, Risaralda, Colombia. Correo electrónico: oparra@uc.edu.co
} 


\section{Resumen}

Teniendo por objetivo establecer cómo se relacionan los empresarios de Risaralda con la construcción de la paz territorial en el departamento -especialmente en los municipios de las zonas más afectadas por el conflicto armado en Colombia (Zomac)-, se realizaron 25 entrevistas a empresarios y actores gremiales, territoriales y estatales de diversa índole. Esto permitió conocer que, si bien existe un interés de buena parte del empresariado (y de sus gremios) en este departamento para vincularse con el mecanismo de Obras por Impuestos y con los incentivos tributarios, como manera de aportar en las Zomac en favor de la construcción de la paz territorial, su proceso de implementación ha sido lento y complejo en el nuevo ambiente de la paz con legalidad.

Palabras clave: empresas, Obras por Impuestos, Zomac.

\section{Abstract}

With the aim of establishing how Risaralda entrepreneurs relate to the construction of territorial peace in the Department -especially in the municipalities of the areas most affected by the armed conflict in Colombia (ZOMAC)-, 25 interviews were conducted with entrepreneurs as well as trade union, territorial, and State actors of various kinds. This allowed us to assess that, although a large part of the business sector (and its trade unions) in this Department are interested in using the Public Works Tax Incentives Mechanism as a way to contribute in the zomac in favor of the construction of territorial peace, its implementation process has been slow and complex in the new environment of "peace with legality".

Keywords: business sector, tax works, zOMAC. 


\section{INTRODUCCIÓN}

¿Fue, es y será el Eje Cafetero un remanso de paz? Ni lo uno, ni lo otro. Ni el Eje Cafetero ni Risaralda han sido ese oasis en medio de la violencia colombiana. Han sido, son y seguramente serán parte de ella y sus evoluciones. No lo fue en la violencia (ubicada tradicionalmente entre 1946-1953, pero la cual siguió), ni lo ha sido en las épocas de las guerrillas y los paramilitares, más recientes; tampoco cuando se miran las estadísticas de violencia general. Muchos libros, textos y datos (Medicina Legal, s. f.) se alejan, entonces, de lo que creen algunas personas sentadas en ciertos escritorios del orden nacional. Tras esta mirada se explica la exclusión de absolutamente todo el Eje Cafetero, por ejemplo, de los Programas de Desarrollo con Enfoque Territorial (PDET).

Esto revela por qué solamente fueron incluidos cuatro municipios, de catorce, en las Zonas más Afectadas por el Conflicto Armado en Colombia (Zomac). A lo largo de las entrevistas que se reseñan en el presente texto, diversos actores discutieron la no inclusión de otros municipios - por ejemplo, Guática o Apia en Risaralda, más otros de Caldas- y cuestionaron que, cuando se habla de Zomac, da la impresión de que se olvidó la presencia paramilitar en la zona. Son enfáticos al decir: "igual fue conflicto, de donde venga fue conflicto armado" (J. H. Echeverry, comunicación personal, 30 de agosto de 2019); y se desbarata, entonces, el mito citado: por lo menos medio departamento, siete municipios, debieron ser declarados Zomac. "En los últimos 20 ańos abandono total, primero, por un conflicto armado que las entidades públicas o privadas no podían entrar, y segundo, porque no ha habido dolientes que estén pendientes del desarrollo socio económico del corregimiento" (D. Mejía, comunicación personal, 16 de agosto de 2019).

A esta memoria del conflicto armado interno se agregan reflexiones sobre la complejidad territorial de un departamento que tiene buena parte en el Chocó biogeográfico (Contreras, 2013), la existencia de barreras geográficas y la insalubridad. "La gente no quiere estar ahî" menciona un entrevistado; otro agrega que es una zona geográficamente difícil, lo que obstaculiza la comunicación, especialmente después de Apía, ya que es una vía con trabajos inconstantes donde cuesta mucho construir una carretera por las fallas geológicas; también se mencionan las dificultades de 
acceso a las comunidades rurales, principalmente a las indígenas, por la geografía selvática y condiciones geológicas. Buena parte de Risaralda es Chocó, aunque más en lo geográfico que en lo social.

Aclarado esto, es bueno recordar que aún se está construyendo la Colombia de la Constitución de 1991, la Colombia de los Derechos.

Cuando comenzó todo este avance de la participación, en los derechos humanos, se volvió incluso una política, en muchas empresas de gran tamaño, la cuestión de la defensa de los derechos humanos. [...] Así como entró en la formación propia de las fuerzas castrenses que las repelían, por eso tengo un concepto que las veíamos, ahora se vuelve una parte importante de la doctrina y crearon, además, una dependencia, porque hubo un apoyo grande del Gobierno de Estados Unidos para la cuestión de esto, de lo de ahí, de difundir y de crear los mecanismos, la capacitación en derechos humanos, y pusieron un general al frente de eso. Yo recuerdo el batallón San Mateo, porque cuando yo estaba en la presidencia de la Universidad Libre hicimos un convenio donde la gente trabajaba derechos humanos y personal uniformado iba a dictar las charlas. [...] Sobre estos temas, para las acreditaciones de las empresas, los que ya querían aspirar para ser de clase internacional que la ONU exigía. Antes los derechos humanos eran una obligación simplemente estatal, gubernamental, no esta cuestión de lo global voluntario; [esto] llegó también al sector privado, y se remitió en el sector productivo. (J. Cortés, comunicación personal, 26 de julio de 2019)

O lo que algunos llaman, una Colombia garantista, en la que apenas van emergiendo de estas comunidades alejadas de los centros, el paso lento a "la organización de las comunidades, porque [son] unas comunidades dispersas, anárquicas pues no tienen una vocería que se haga escuchar" (Cortés, 2019) o como lo sintetiza uno de los alcaldes de Zomac entrevistados:

[Hay] zonas difíciles que el Estado ha abandonado. El Estado las militariza, mete a la cárcel, las desmina, pero las abandona. Si el Estado no va con la fuerza 
pública de la mano con inversión social y con el apoyo de la comunidad, que es lo más importante, no genera la confianza que se requiere. [Se necesita] que la gente crea en las instituciones, porque hay zonas del país donde la gente no cree en el Estado, porque no ha habido una inversión; los ha abandonado, porque ha sido una fuerza pública que no ha actuado en beneficio de la comunidad, sino que va y los atropella, va y masacra, [genera] los falsos positivos. Porque masacres no hay solo de la guerrilla, o de los paramilitares, sino del mismo Estado, entonces los abandona. El Estado tiene que tener una continuidad total en esas zonas donde ha entrado y ha recuperado la paz y la tranquilidad; pero si las abandona, si las deja a la merced de otros grupos, llámense ya no Farc, sino disidencias "tales", o paramilitares "tales", sino otros; si no hace esa presencia constante, mañana vuelve y se jode la zona. (J. Uribe Flórez, comunicación personal, 2019)

Esta es la Colombia/Eje Cafetero/Risaralda que va evolucionando, que va a llegar, tras 52 años de su existencia y tras 34 años de fallidos procesos de paz, a los acuerdos con las Farc. Estos van a impulsar las correcciones ${ }^{1}$ de los procesos anteriores, pues se han concentrado en la reincorporación de individuos -algo importante-, pero olvidando lo esencial: la necesidad de superar las causas objetivas de las que ya se hablaba en 1982.

Como lo dice una persona que ha recorrido casi toda su vida entre el sector público y el privado:

Violencia importada [...]. Perduran los elementos iniciales: atraso, pobreza, incomunicación, dificultad de encontrar liderazgos positivos y honrados [...]. Una corrupción rampante [...]. Peor en las zonas más necesitadas [...]. Pluricausalidad [...]. Se puede negociar con unos seńores, pero, ¿y las causas objetivas? (J. Ángel Mejía, comunicación personal, 30 de julio de 2019)

1 Esta investigación y este texto es un homenaje a la Comisión de Superación de la Violencia (1992), Pacificar la paz, lo que no se ha negociado en los acuerdos de la paz, IEPRI, UN, CINEP, Comisión Andina de Juristas y Cecoin, Bogotá. Los esfuerzos académicos por llamar la atención sobre ajustes que buena parte de la dirigencia -especialmente política- del país, se niega a hacer. 
Es decir, de la necesidad ineludible de construir la paz territorial.

Viene entonces la creación y adopción de incentivos tributarios para cerrar las brechas de desigualdad socioeconómicas en las Zomac, a través de la Ley 1819 del 29 de diciembre de 2016 (Reforma Tributaria). Entre dichos incentivos se crea el mecanismo Obras por Impuestos (artículo 238), mediante el cual -para describirlo de manera breve- se invita a los medianos y grandes empresarios a invertir hasta el $50 \%$ de su impuesto de rentas en la ejecución directa de proyectos de inversión prioritarios en salud, educación, energía, agua potable, alcantarillado e infraestructura vial, en dichas zonas, deduciendo hasta en un $50 \%$ el valor a pagar por impuesto a la renta. También se crean incentivos a la inversión privada y a la micro-pequeña, con el fin de crear empresas y garantizar incentivos progresivos del impuesto de renta hasta del $75 \%$ al año $2027^{2}$.

Es importante explicar el objetivo del mecanismo Obras por Impuestos dentro de la agenda de paz. Este consiste en impulsar la inversión al involucrar al sector empresarial -en persona jurídica o natural con capacidad económica- en los procesos de transformación de las Zomac, a través de una alianza de lo público con lo privado. De esta manera se busca reactivar económicamente los territorios y fortalecer la institucionalidad, a través de contratación privada, con el fin de potenciar la naturaleza de los recursos de públicos a privados, facilitando y agilizando la construcción de obras. Con estas acciones igualmente se busca prevenir nuevos ciclos de violencia.

Finalmente, cabe anotar que el nuevo Gobierno (Iván Duque) impulsó una reforma del mecanismo, y en diciembre del 2018 fue aprobada la Ley 1943 del mismo año, llamada Ley de Financiamiento, que incluyó todo un capítulo en relación con las Obras por Impuestos ${ }^{3}$.

2 Toda la información se encuentra disponible en el sitio web: http://www.renovacionterritorio.gov.co/ Publicaciones/obras_por_impuestos

3 Que, por cierto, es un modelo peruano. Véase Obras por impuestos: Balance a una década de su vigencia, disponible en: https://blogposgrado.ucontinental.edu.pe/obras-por-impuestos-balance-a-una-decada-de-su-vigencia 
Uno de los cambios más importantes que la Ley de Financiamiento le hace al mecanismo de Obras por Impuestos es permitir que la naturaleza jurídica dé los recursos para la ejecución, así como que los modelos de subcontratación correspondan a la naturaleza jurídica del contribuyente. Esto abre la puerta para que se usen modelos de contratación privada y se flexibilice el mecanismo. [...] Se establece la posibilidad que puedan ser considerados proyectos que no necesariamente estén localizados en las Zomac. Lo anterior, siempre y cuando resulten estratégicos para la reactivación económica y social de las Zomac o alguna de ellas. [...] Extendió los sectores sobre los cuales se pueden desarrollar proyectos de Obras por Impuestos. Entre los nuevos sectores se encuentran: bienes públicos rurales, adaptación al cambio climático y gestión de riesgo; pagos por servicios ambientales; tecnologías de la información y comunicaciones; infraestructura productiva; infraestructura cultural e infraestructura deportiva. [...] Establece que los compromisos de inversión adquiridos en los convenios de Obras por Impuestos no podrán superar el $30 \%$ del patrimonio contable del contribuyente, para lo cual se tendrá en cuenta el patrimonio del año inmediatamente anterior. [...] Crea la figura de Títulos para la Renovación del Territorio (TRT), como instrumento de remuneración a la luz de la ejecución efectiva del proyecto de Obras por Impuestos. Dichos títulos tendrán la calidad de negociables. Los TRT podrán ser utilizados para pagar hasta el $50 \%$ del impuesto de renta. [...] Se abre la posibilidad para que las personas jurídicas que tengan deudas por concepto del impuesto de renta lo puedan pagar por medio de TRT. (Fundación Ideas para la Paz [FIP], 2019)

En términos más prácticos, en la voz de un empresario involucrado con el mecanismo:

Con los flujos mensuales que tiene de provisión de renta se puede empezar a hacer la inversión a cambio de esos títulos, que el día de mañana le va a servir para pagar la renta [...]. Y entonces todo lo que va invirtiendo, como es en un proyecto vigilado por el Ministerio de Hacienda y por la Agencia de Renovación del Territorio (ART), la fiducia le va dando el visto bueno, le van entregando los Títulos (o el certificado) de que esa plata está invertida -de pronto es más trabajo para el contador- [...]. Ya no depende del ciclo fiscal, usted puede sentarse con un alcalde y decirle: ¿qué necesita del plan de 
desarrollo que esté dentro de obras por impuestos? Y el alcalde le dice, por ejemplo: "necesito un puesto de salud". Entonces usted puede decir "venga presentemos el proyecto que lo apruebe la ART y el Ministerio de Hacienda y empecemos a construir ya, no esperemos a que termine la vigencia fiscal" [...]. Para la empresa es mucho mejor en la medida en que usted decide en qué quiere invertir. (J. Franco, comunicación personal, 2019)

Dichos cambios generaron una serie de dudas jurídicas respecto a las nuevas reglas de juego. De hecho, extraoficialmente, los entrevistados conocieron un decreto reglamentario de la nueva ley que eliminaba inversión en las Zomac, con lo cual el Eje Cafetero -y otras regiones similares- serían excluidas. Ante tal actitud, los tres gobernadores del Eje Cafetero alertados al respecto respondieron con gestiones. Dicha ley posteriormente cayó en la Corte Constitucional al momento de la investigación (octubre 16 de 2019) y se anunció que sería presentada de manera idéntica por el Gobierno Nacional en los meses siguientes ${ }^{4}$.

Es así como se llega al objetivo que, convertido en pregunta, guía la investigación (abril a octubre de 2019): ¿cómo se relacionan los empresarios de Risaralda con la construcción de la paz territorial en su departamento? Especialmente frente a las posibilidades de Obras por Impuestos o de apalancamiento tributario que ofrece dicha Ley y la nueva Ley en las Zomac.

\section{Metodología}

Esta es una investigación cualitativa; por ello, el método usado es el fenomenológico. Se realizaron 25 entrevistas a profundidad, con un modelo semiestructurado, a: un abogado asociado con comunidades indígenas, alcaldes de los municipios Zomac, candidato a alcaldía de municipio Zomac, revisor fiscal, directores ejecutivos de gremios y del Comité Intergremial Risaralda, exalcaldesa de un municipio Zomac, ex CEO Empresarial, un expresidente del Senado de la República, un gerente

4 En diciembre de 2019, la ley estaba caída — seguía en vigor la anterior- así como el decreto reglamentario -también vigentes los anteriores- pero, según parece, el Gobierno Nacional insistía en concentrarse solo en municipios PDET y excluir a las Zomac. Finalmente, el 27 de diciembre se expidió una reformada Ley 2010. 
regional, el obispo de la Diócesis de Pereira, el presidente ejecutivo de la Cámara de Comercio de Pereira, propietarios de empresas, el propietario de un medio masivo de comunicación, secretarios departamentales [Gobernación] y secretarios municipales.

Una vez realizada la obtención de la información, se procedió a su transcripción y organización. Esto nos llevó a categorizar por nivel de actores: actor contextual, actor gremial, actor empresarial, actor estatal y actor territorial. De esta clasificación se desprenden combinaciones tales como: actor estatal/nacionaly actor estatal/contextual. Y a partir de allí realizamos la integración sistemática que refleja la presente síntesis a manera de artículo5.

\section{Resultados}

Nuestro objetivo fue obtener información sobre empresas para determinar cómo se involucran en la construcción de paz en los municipios de Risaralda (asociados con las Zomac). Según revelan los actores de la presente investigación, la primera convocatoria de Obras por Impuestos en toda Colombia, con las alcaldías y gobernaciones, fue a quema ropa (P. Certuche y D. López, comunicación personal, 2019) con fechas perentorias, en un momento en el cual las gobernaciones solo pudieron ofrecer acceso a sus Bancos de Proyectos, donde los había.

Inicialmente eran Mistrató y Pueblo Rico [...]. Luego, logramos que incluyeran a Quinchía [...]. Hubo una gestión con la asamblea, con parlamentarios, con presidencia y, finalmente, lo lograron incluir [...]. Porque están los unos y no los otros [...]. Pueblo Rico y Mistrató tenía algo más reciente de Farc (y del) EPL, Quinchía tenía Farc hasta el 2006, el paramilitarismo fue hasta el 2004 [...]. Ya en el 2015-2016 hubo presencia del epL otra vez [...]. Se creía que

5 El presente texto se expresa uno de los dos ejes de la investigación: Identificar los procesos usados por las empresas de Risaralda para aportar a la construcción de la paz, dentro de línea de investigación Modelos de gerencia regional de la Fundación Universitaria Comfamiliar. Se contó con el respaldo del semillero de investigación Paz + Empresas, entre el 4 de abril y el 23 de octubre 23 de 2019, conformado por los estudiantes: Tatiana Aguiar (Administración de Empresas), Darío Andrade, Lizeth Salazar y Steven Bueno (Administración Financiera). La lectura y comentarios al texto son de los profesores-doctorandos de la uc Dolly Patricia Rodríguez Flórez, Olga Lucía Hurtado Cardona y, externamente, de Leandro Vivas Fuentes. La revisión final la realizó Claudia Esperanza Castaño Montoya. 
estaba más calmado, en tanto Pueblo Rico y Mistrató eran más corredores [...]. Creíamos que iba a ser una bonanza financiera. (Uribe Flórez, 2019)

A lo cual, el alcalde de Balboa agrega:

La gobernación nos da una manito con la Secretaría de Desarrollo Económico y nos presenta los empresarios; nos reunieron a los 4 alcaldes con empresarios. Especialmente con la Empresa de Energía. Si la gente de Obras Civiles de la EEP no se mete hubiera sido muy complicado. Ya tenían la experiencia en otras partes del país. Los 4 alcaldes empoderamos a los secretarios de Planeación. Recuerdo que presentamos Balboa y Pueblo Rico. (J. Pulgarín Montoya, comunicación personal, 2019)

Un expresidente de la Asociación Nacional de Empresarios de Colombia (Andi) relata que la idea les había sonado a las empresas Frisby, Magnetrón y Gonzalo Salazar, en total a unas 10 o 12 empresas; incluso hubo una junta ampliada de la Andi. También manifestó que se había encontrado con una gran ausencia de proyectos elaborados a nivel estatal; incluso las empresas de Risaralda se fueron a invertir a otros departamentos como Nariño (Empresa de Energía de Pereira en Tumaco). Señaló que tuvieron que asumir los ejercicios de planeación y destacó la falta voluntad política, una ausencia de pensar a largo plazo. Corredor, afirma que: "No tenemos en fase tres programas importantes para esa región. Nos hace falta la planeación para que los empresarios tengan una actitud de confianza [...], programaciones serias para el desarrollo de las zonas vulnerables" (R. Corredor, comunicación personal, 2019).

Según Tuirán y Trejos (2017), una situación que se presentó en todo el país fue la siguiente:

El éxito de este proceso no está en la implementación centralizada de lo acordado, ni en una implementación descentralizada sin regulación alguna; sino, principalmente en el fortalecimiento de la democracia local, la participación ciudadana, las capacidades administrativa y técnica del nivel local. Estos elementos son fundamentales en la construcción del Estado de 
Derecho con una sólida institucionalidad, lo que en el mediano y largo plazo evitaría el surgimiento y evolución de rentas criminales, controladas por actores legales e ilegales que buscan capturar el Estado en el plano local con el fin de ponerlo en función de la satisfacción de intereses privados en detrimento del desarrollo y fortalecimiento de lo público.

En agosto del 2018, el candidato de un partido político que se había mostrado en contra de la generalidad del proceso de paz liderado por el anterior presidente, asumió la dirección del Gobierno Nacional. En este escenario, el alcalde de Quinchía, Risaralda, señala:

El Estado se inventó las Zomac, pero con una credibilidad en el Gobierno anterior. Teníamos la certeza de que a esos municipios iba a llegar una inversión. Pero eso en la actualidad es una mentira. Cuando usted ve el panorama nacional, ve por ejemplo una Jep ilíquida y sin recursos. Entonces el Gobierno Nacional, que no cree en la paz, que es más guerrerista que pacifista, nunca pudo acabar el proceso de paz vía Congreso, entonces cómo lo está acabando: vía presupuesto. Entonces si usted no le gira plata a la JEP, restitución, victimas, reinserción, para que funcione, pues usted lo va acabar por obvias razones presupuestales: por desangre presupuestal. Una cosa es el análisis antes de y otra es después de. Todo el mundo está cumpliendo a lo mínimo que da la norma. Hasta el 2017 el ritmo era otro, de ahí para arriba cambió mucho, el acelere es el mínimo, diría yo que hasta asfixiarlo. (Uribe Flórez, 2019)

Existen voces de alto nivel nacional y local, supremamente pesimistas, tal como se evidencia en la afirmación de Marulanda:

La construcción de paz ha fracasado. No está en su discurso, ni en sus intenciones, ni en sus afectos, ni en su trabajo, ni en sus presupuestos [...]. Para construir la paz en Colombia se necesitan cinco gobiernos de dedicación exclusiva iy bien que ese sueño lo merece! Pero en la consciencia de nuestras gentes no cabe eso tan grande. (I. Marulanda, comunicación personal, 2019) 
Empero, el mecanismo en sí es formidable, pero complejo, así lo reconoce la mayor parte de los entrevistados. Según Osorio, este requiere:

\begin{abstract}
Alinear muchos actores: las empresas (interesadas en hacer desarrollo), la ART, los ministerios, el municipio [...]. Hay que invertir en construcción de factibilidades: las empresas dicen: "listo, pero, ¿dónde están los proyectos formulados? [...] Debe formularlo la gobernación, los municipios; las empresas pueden, pero deben cumplir toda la formalidad de viabilidad del sector; por ejemplo, la secretaría de infraestructura, el ministerio. (D. Osorio, comunicación personal, 2019)
\end{abstract}

Es claro que existen serios problemas en relación con la articulación institucional entre el Gobierno Nacional y las autoridades locales y regionales (Medina y Martínez, comunicación personal, 2019).

Nosotros nos metimos como alcaldía. La gobernación poco, solo al final, y eso porque hicimos la fuercita con el Comité de cafeteros. Muy pendientes. Desafortunadamente siempre buscan es ejecución (la gobernación) y a nosotros no nos importa quién la haga, llámese gobernación, llámese comité, llámese empresa privada; para nosotros lo importante es que lleguen las obras al municipio. (Pulgarín Montoya, 2019)

Tal vez la mayor dificultad ha sido el aterrizaje espacio-territorial: "en las Zomac, las administraciones municipales y departamental no le han puesto cuidado. Por otro lado, las empresas privadas todavía tienen el paradigma de que el corregimiento es guerrilla" (Mejía, 2019). A ello se agrega la llegada de nuevas administraciones al momento de escribir este texto, más la pandemia.

Frente a las claras debilidades de los municipios, especialmente de los periféricos y de la gobernación -que constituye un fenómeno nacional-, Ángel Mejía, afirma que: "Las gobernaciones no tienen presupuesto, son un premio de consolación, no tienen pies y cabezas, deberían ser unos entes más poderosos. Aquí realmente el poder está 
centrado en los municipios, y se están muriendo casi todos" (comunicación personal, 30 de julio de 2019).

También se suman las debilidades del capital social. Sobre este, Mesa agrega:

Nos falta la articulación [...]. El bien es silencioso. Nos falta acercarnos más. Debe haber instituciones desde el empresariado y sector productivo, con algunos exdirigentes, por ejemplo, pro-Antioquia, que marque el camino, independientemente de lo que cada cierto año pase en términos políticos, para que se trace una línea [...] Falta una visión de Risaralda. (G. Mesa, comunicación personal, 2 de octubre de 2019)

A pesar de estas debilidades manifiestas, lo que relatan los alcaldes entrevistados se resume en una frase de un actor territorial: "la debilidad de las secretarías se contrarresta con la voluntad del alcalde". (Echeverry, 2019) Casi que coloquialmente podríamos decir que quien quiere puede. Al respecto, Pulgarín Montoya menciona:

El proyecto es un tema neto del municipio, se hizo a través de una consultoría y costó unos 50-60 millones. Hacemos un esfuerzo muy grande, se me come en gran medida el presupuesto de Planeación [...]. Tenemos un equipo de proyectos acá en Pereira. [...] (Si) yo no hago (una) obra de 200 millones, (la que quieren por) la inmediatez. Entonces, el alcalde es muy malo, no están mirando qué el alcalde hizo con esa plata de tres proyectos, que a futuro se convierten en 10 o 15 mil millones de pesos para el municipio, que hay que esperar unos tiempos prudentes mientras llegan las convocatorias. [...] (Ya en el proceso) me di cuenta que si usted no cuenta con el cumple del DNP, que es un articulador de todos los ministerios, no hacemos absolutamente nada; si los municipios no tienen eso no hay nada. [...] la preinversión es fundamental. [...] (Por eso nosotros) contactamos un equipo de consultoría que se compromete a hacer el proceso, y a que el cumple se dé en Bogotá, que ha sido capaz de moverse, de tener contactos en Bogotá, en un año y medio logramos llevar 10 mil millones de pesos. (Pulgarín Montoya, 2019) 
Otros actores puntualizan en la relativa facilidad de los formatos que se requieren para las obras que esperan gestionar los municipios:

Los proyectos de vías, son proyectos tipo bajar el formato y llenarlo, tal cual ha sucedido con la mayoría de las obras por impuestos que se han hecho en Colombia. [...] casi el $80 \%$ son vías, $5 \%$ son saneamiento básico, acueducto, alcantarillados, pozos sépticos, y el otro $5 \%$ sector educativo. [...] en gran medida porque eran los proyectos que tenían las alcaldías en fase iII para las OCAD-PAZ; simplemente cambiaron unos certificados que tenían, bajaron el formato y lo pasaron para otra plataforma. (Certuche y López, 2019)

En el proceso, la empresa le entrega el dinero a la fiducia (generalmente a Fiduprevisora), sobre la cual recae en gran parte hoy la responsabilidad de poner a andar los tres ejes de las obras: interventoría, gerencia y ejecutor de la obra. La interventoría pone las reglas con el ministerio relacionado; la gerencia y el que vaya a construir salen de un modelo que coloca la fiducia (Certuche y López, 2019). Hay empresas que han asumido la gerencia del proyecto, lo cual es un gran riesgo, pues depende de su experticia.

A continuación, se describen las empresas que se han relacionado con el tema en Risaralda; ambas con vigencia en el 2019 (año gravable 2018).

\section{La Empresa de Energía de Pereira (EEP)}

La EEP está a la vanguardia (C. Nilton y Y. Claros, comunicación personal, 10 de mayo de 2019). Los entrevistados consideran que la empresa se vinculó debido a un cambio de estrategia y en la manera de pensar y actuar: no medir todo bajo el esquema financiero, lo cual es un cambio desde el 2015. Así han desarrollado una estrategia de generar valor compartido y desarrollo sostenible. Es un impulso desde la base de la empresa, la cual hace conciencia de que el negocio asociado a la energía está cambiando. Apuntar a las futuras generaciones. Buscar el equilibrio económico, social y ambiental. 


\begin{abstract}
Algo que resaltaron es que "el modelo le apunta a la transparencia: una reforma tributaria se pierde por la corrupción”. Así lograron articularse con Balboa, el municipio incluido en las Zomac, el único que ha logrado concretar una obra por 4800 millones de pesos, más de tres kilómetros de vías terciarias (o interveredales): La Palmera (Monos) y La Cancha (Puracé) 6
\end{abstract}

\title{
Apostar
}

Como sucede con la EEP, el componente emocional -si se quiere- es clave:

Desde la misma esencia, los socios de los miembros de la junta directiva tienen un compromiso: nuestra Responsabilidad Social Empresarial ${ }^{7}$. [...] tenemos una herramienta que nos permite hacer un impacto directo. En las comunidades donde nosotros hacemos presencia tenemos un impacto directo. (Franco, 2019)

La empresa Apostar había conocido la experiencia de la empresa de apuestas del Tolima, la cual había participado en la primera oleada de Obras por Impuestos de 2018 (Renta, 2017). Así, partiendo de la introducción que le hiciera su revisoría fiscal -figura empresarial clave en estos procesos- comenzaron a acercarse a los municipios y conocieron los proyectos que, por ejemplo, existían en Quinchía, de Caminos Ancestrales (una obra de varias decenas de miles de millones de pesos). Finalmente llegaron a Quinchía, donde existían proyectos acordes con sus posibilidades presupuestales. Los proyectos que este municipio presentó no fueron aprobados ${ }^{8} \mathrm{y}$ tuvieron que buscar otras opciones. $\mathrm{Al}$ respecto, Franco agrega:

6 Empresa de Energía de Pereira S.A. E.S.P.; mejoramiento de vías terciarias en el municipio de Balboa, Risaralda. El costo del proyecto (con ajuste a costos incluido) fue de \$ 4773723 523.00. Información (generalmente) disponible en: http://www.renovacionterritorio.gov.co/

7 Apostar tiene una fundación, un hogar para el adulto mayor en condiciones de calle, donde se le garantizan sus necesidades básicas. Entre otras, apoyan una fundación que auxilia las personas que reciben diálisis.

8 Otras fuentes, que pidieron no ser nombradas, señalan que no se pudo dar un trabajo de equipo entre la alcaldía -dadas las debilidades de las áreas de planificación que, de hecho, ni siquiera se pueden dedicar exclusivamente a tan importante tema- y la organización que Apostar contrató para aterrizar el proceso. 
Hace algunos años le escuché al director Nacional de Planeación, Simón Gaviria, que de cada 100 pesos que se recogen de impuestos en Colombia, cerca de 82 se quedan allá y solo 18 vuelven a las regiones. Se quedan allá en administración, en burocracia; entonces, decidimos generar impacto en un departamento cercano, por ejemplo, Quindío. Intentamos Salento (y Pijao), y tampoco hubo forma. Entonces yo les propuse: “pues vámonos para el Tolima que allá hubo proyectos bien estructurados para el beneficio de esos municipios". [...] había tres proyectos de dotación escolar, deportiva y de computadores; escogimos el de dotación cultural, de dotación de uniformes (artísticos, de baile) a colegios de varios municipios (alrededor de 360-380 millones) ${ }^{9}$. (Franco, 2019)

El entrevistado manifestó que se escogieron esos proyectos porque su meta era impactar "la educación de las personas que son el futuro; distraer a la gente de la calle, los vicios y de cualquier cosa (y en esas zonas, de los actores armados)" (Franco, 2019).

\section{Pez casta}

Desafortunadamente no fue posible dialogar directamente con los responsables, pero durante la investigación se conoció que se trata de una truchera ubicada en la vía Mampay, kilómetro 6 Mistrató, que produce 2 a 3 toneladas de pescado y exportan a Estados y Canadá. Se indagó sobre por qué funcionó y la respuesta de un actor territorial fue que "el dueño conocía la zona” (Mejía, 2019).

Ese es el balance, muy parecido al nacional:

9 Apostadores de Risaralda, Sociedad Anónima (Apostar S. A.) apoyó el fortalecimiento de la actividad artística y cultural en las instituciones educativas, con la dotación de implementos para el área artística en el municipio de Santa Isabel, Tolima. El costo del proyecto (con ajuste a costos incluido) fue de \$ 361258573.00 , curiosamente es uno o el proyecto aprobado más pequeños. Información disponible en: http://www.renovacionterritorio.gov. co/descargar.php?idfile $=25215$ 


\begin{abstract}
Durante el primer año de la implementación de Obras por Impuestos (2018, año gravable 2017), el cupo establecido por el Consejo Superior de Política Fiscal (Confis) fue de $\$ 250000$ millones y fueron aprobadas 23 solicitudes por un valor total de $\$ 220616$ millones. Estas obras están siendo ejecutadas en 25 municipios de los 344 que integran las Zomac, con un impacto mayoritario en los departamentos de Antioquia y Nariño. (FIP, 2019)
\end{abstract}

Para el segundo año (2019, año gravable 2018) -pero aún con las reglas de juego de la primera ley- se integran las dos empresas de Risaralda: la que invierte en Balboa y la que llegó al Tolima. En esta ocasión se aprobaron 42 proyectos y la inversión llegó a 247319 millones, casi todo el cupo. En este periodo se resalta una característica: si bien el $50 \%$ de las obras se ejecutan en municipios Zomac, solo el $25 \%$ de la inversión llega a estos, pues la prioridad del actual Gobierno Nacional son las PDET (Agencia de Renovación del Territorio [ART], 2019). Es decir, que se podría pensar que la existencia de una sola Obra por Impuesto en Risaralda y la vinculación de solo dos empresas es un dato poco halagüeño, pero realmente hace parte del contexto nacional.

A la fecha ${ }^{10}$ persiste la incertidumbre, pues tras la caída de la Ley de Financiamiento -como se relató- se creó un borrador del decreto reglamentario (entre septiembre y octubre del 2019) en el que se pretendía reducir las Zomac de 344 municipios a 170; es decir, dejar solo las que estaban en el PDET. Esto se vislumbraba en el documento Paz con Legalidad, y que hubiera dejado a los tres departamentos del Eje Cafetero totalmente por fuera de las Zomac. Se alertaba que, en la nueva Ley de Financiamiento, una figura similar resucitaba.

Sumado al contexto del rompimiento del proceso de paz con el eLN (segundo semestre del 2018), con histórica presencia en los municipios Zomac (sin contar a Balboa, pero sumando a Guática) (Parra, 2007), las disidencias de las Farc y los demás actores armados provocan un retroceso y emerge una parte del ciclo que ha mantenido estos territorios como caldo de cultivo para los violentos: la inseguridad

$10 \quad$ Noviembre 14 de 2019. 
para invertir en la zona. Es atrasada porque es insegura; y es insegura porque es atrasada. A esto se suma la feudalización familiar de ciertos territorios.

Yo creo que la gente no está convencida de la seguridad. Los territorios también se están volviendo propiedad de unas personas, ¿̨me entiende? Ya hoy, digámoslo, por poderes, no es por el departamento, sino por el territorio por un municipio $\mathrm{X}$ o Y. O sea, se van volviendo unos sitios, solo de unos grupos; no sé cómo hacen. (Echeverry, 2019)

Se aduce -no con el entusiasmo inicial- que hay problemas de diverso tipo:

La gente no quiere tomar riesgos. El riesgo es que usted se mete a una zona donde es complicado ir; no hay servicios públicos, no hay comunicación. [Están] los riesgos de que a su empresa le corten la luz, de que no pueda sacar el producto. (Ángel Mejía, 2019)

Tal cual han insistido diversos expertos, tal vez una de las revoluciones que necesita el país es la de las vías interveredales e intercorregimentales: "Las vías no están. El tema vial no está para que una empresa empiece a [tener] un desarrollo en esa zona” (Echeverry, 2019).

Además, ha regresado la desconfianza. Uno de los temas más complejos en estos procesos.

¿Sabe cuál es el tema? La confianza. Pero no la confianza de seguridad, sino de la confianza de los que administran el territorio hoy. Yo digo que es más la confianza, porque cuando usted habla del sector público, usted le pone a una persona la crucecita de la corrupción. Yo creo que ese discurso hay que quitarlo, porque hay tanta corrupción en el sector público como el privado; y si el público es corrupto, es porque el privado también ayuda. (Echeverry, 2019)

Esta postura es reafirmada por otros entrevistados: 
La amenaza de la corrupción está entonces en el escenario. Incluso se recuerda que se ha usufructuado el tema de la paz para beneficio personal: el caso del sobrino de Iván Márquez, tuvo que venir la comunidad económica europea a preguntar dónde está esa plata, lo cual alimenta la desconfianza que hay de ambas partes. (A. Sánchez, comunicación personal, septiembre de 2019)

También se analiza la voluntad del alcalde y sus intereses particulares: es que la obra no me genera, es que lo va a ejecutar es un privado. Entonces, el alcalde no tiene interés poner un ingeniero, y no le va a poder decir al privado: "deme el 10 o deme el 15 (\%)”. (Mejía, 2019)

Ante la pregunta: ¿es posible que el trasfondo de las dificultades con algunas administraciones sea que los alcaldes no manejan la plata?, uno de los actores directos responde: "sí, es posible. La plata la maneja una fiducia, con supervisión del Ministerio de Hacienda, porque se hacen invitaciones abiertas privadas. Pero, finalmente, quien toma la decisión es la empresa, con la fiduciaria y con la ART" (comunicación personal, 2019).

Según Osorio, "el tema es grave, pues se requieren proyectos muy bien formulados, una gestión de confianza, porque el empresario apuesta por ellos solo si la gestión territorial les genera transparencia y confianza" (Osorio, 2019).

Cuando se mira el importante número de empresas (y la variedad) que le han apostado las Zomac (y a las PDET), se reflexiona:

Vieron un potencial en estos territorios que antes no se había explorado; no sé si algunas directamente por las potencialidades del territorio, porque son territorios que están geoestratégicamente ubicados y que los conecta con territorios de alto desarrollo. Siento que todos estos, de alguna manera, son ejes. Por ejemplo, Pueblo Rico está en camino al Chocó, es un eje importante de comunicación con el pacífico colombiano, entonces tiene mucho potencial porque está geoestratégicamente ubicado. De alguna manera, Mistrató también es un corredor estratégico. Entonces creo que este seguramente es 
un factor que tuvieron o deberían tener en cuenta las empresas que quieran invertir en estos territorios; ver en la población de estos territorios un potencial que no se ha tenido casi en cuenta en el desarrollo territorial de estas zonas. (H. Victorino, comunicación personal, 9 de julio de 2019)

Así lo amplían actores que habitan las zonas:

Con el proceso de paz, muchas personas han regresado al corregimiento (San Antonio del Chamí), a las fincas; han metido ganado y han comprado otras fincas. Se cuenta con la presencia de la policía en el corregimiento, el ejército también se mantiene; pero no hay una propuesta de desarrollo económico. [...] primero los beneficios tributarios, venderles primero el tema de seguridad; segundo, servicios públicos: es más barato allá que acá; tercero, mirar a Mistrató por su posición geográfica: usted se va a ahorrar dos horas para ir a Medellín en 2021, al pacífico tres horas [...]. Que bueno traerles 2, 3 días (a Mistrató) que aquí hay una zona industrial en el рот, se puede impulsar la máquina plana. En los municipios la gente cuida más su empleo y la vida es más barata. Si nosotros tenemos 100 o 200 empleados dinamizamos la economía. (Mejía, 2019)

\section{Conclusiones}

Existe un interés de buena parte del empresariado (y de sus gremios) de Risaralda en vincularse con Obras por Impuestos como forma de aportar a la paz territorial en el nuevo marco de la paz con legalidad ${ }^{11}$. Empero, los resultados muestran que el mecanismo -el cual en países como Perú tardó años en aclimatarse-aún no se potencia y posee debilidades ligadas al bajo desarrollo de los estados locales, tanto a nivel de las alcaldías, como de las mismas gobernaciones. A esto se suman incertidumbres y hasta amenazas para su desarrollo, provenientes, sorprendentemente, desde el estado central: su creador.

11 Cabe anotar que, hasta donde nuestra indagación alcanza, este es el primer ejercicio que se hace en el departamento sobre este tema. 
La resiliencia de la nación, del complejo pueblo de los colombianos, persiste, y el fuego encendido hace ya 2-3 años, a pesar de las dudas, se mantiene; y una central es, precisamente, la posibilidad de bloquear corrupción:

Lo que tiene esto de importante es que hay una vinculación de la comunidad directamente, cuando hablamos de que yo pago impuestos, de que es que esa plata es de nosotros que tenemos que pagar, eso es muy etéreo, (pero) cuando usted lo concretiza y lo puede utilizar aquí con lo que hizo (esta escuela, este camino), eso ya es muy distinto, porque queda vinculado con un sentido de pertenencia; entre otras cosas para mí es una de las muchas formas de evitar los procesos de corrupción, además (porque usted tiene el control sobre la plática) y estamos hablando de participación, de las veedurías ciudadanas. (Cortés, 2019)

Otros son, incluso, más directos en sus apreciaciones sobre este mal que nos carcome: "el empresario hace rendir la plata: las obras en este país valen el doble por lo que sabemos" (M. Ramírez, comunicación personal, 19 de julio de 2019).

En palabras de uno de los grandes aportantes del fisco en Colombia:

Es un camino para saltarse la corrupción: es una concepción libertaria. La corrupción está porque es un Estado gigante, creado así para que los que han dominado el Estado se sigan llevando el botín: ¿cómo contravenimos eso? Achiquemos el botín, achiquemos el Estado. (Mesa, 2019)

\section{RECOMENDACIONES}

Dentro de las propuestas que traía la nueva ley -caída y en discusión en este instante- estaba la posibilidad de que las Obras por Impuestos se extendieran a municipios no-Zomac y que, además, pudieran articularse regionalmente. Es una postura correcta: "hay profundos desniveles regionales: del Chocó a Risaralda, por ejemplo. No hay visión de región, ejemplo, Antioquia, Valle, Risaralda deberían 
actuar mancomunadamente con el Chocó. Mistrató y Pueblo Rico son los más relacionados con la problemática de esta región" (Corredor, 2019).

Ningún proceso de paz podrá avanzar en Colombia sin los indígenas, sin los afros, sin las comunidades que habitan en las periferias: "no hemos entendido la cultura Chamí, necesitamos entender más esa forma de pensar de ellos. Katio, oficializar esa lengua, es clave para transmitir los valores (AC 3)"12 (Corredor, 2019).

[Hoy] Hay unos derechos de las comunidades minoritarias como la indígena, la afro, que han vivido en esas circunstancias y son factores importantísimos de tener en cuenta; es decir, yo estoy de acuerdo con la intensión de la pregunta de que si no se cuenta con ellos. Y debería tenerse en cuenta su idiosincrasia, porque es un aspecto de tipo cultural, unas tradiciones inclusive ancestrales, que les da línea en la forma de actuar, y si no se tiene en cuenta no se alcanzaría a formar la paz. (Cortés, 2019)

Es urgente superar la queja sobre la "falta información para los empresarios", que "el trámite es engorroso", que hay "desconocimiento de la norma, de las posibilidades" (W. García, comunicación personal, septiembre de 2019); "hay un gran desconocimiento de los beneficios jurídicos asociados a las Zomac" (Nilton y Claros, 2019). Esto se extiende al territorio mismo y a las comunidades que aún no se empoderan:

Ya que usted me lo menciona, será un tema que más bien yo hable con las comunidades, también no lo he hablado directamente con las comunidades, pero puede ser que se haga un ejercicio con las comunidades en particular y con algunos líderes en general para mirar también desde la perspectiva de ellos qué reto, qué oportunidad, retos y oportunidades tanto para la región en general como para ellos como comunidades, pueden ver en este proceso, también que yo sepa no ha habido mucho diálogo al respecto, sería un buen escenario para poner el tema en la agenda con ellos, en la agenda pública del departamento. (Victorino, 2019)

12 Actor contextual. 
Se requiere avanzar sobre las dificultades asociadas con la ausencia de programas de desarrollo:

Necesario, posible y factible a que no tenemos en fase tres programas importantes para esa región. Nos hace falta la planeación. Para que los empresarios tengan una actitud de confianza, programaciones serias para el desarrollo de las zonas vulnerables. Desarrollar el proyecto para que lo viabilice el Ministerio, y la empresa realice la infraestructura, y apoye la fiduciaria. Se requiere un lobby de alto nivel con el Gobierno Nacional: pertinencia, sensibilizar a los tomadores de decisiones, el respaldo institucional, la credibilidad de las empresas. En la medida en que se logre implementar, los empresarios se meten. (Osorio, 2019)

Se necesita establecer claros canales Zomac-empresarios. “¿Las necesidades están bien estudiadas? ¿Cuál es la mayor necesidad?” (Ramírez M., comunicación personal, 2019).

Con los proyectos [hay que] ir y sentarse con los empresarios, que le boten el miedo a eso, que es que no conocemos mucho la normatividad, normas de exenciones tributarias, dificultades con el estado. No hay claridad suficiente. El empresario está centrado en la registradora, el tema es del financiero, el contador, y el tributarista: la revisoría fiscal, los temas tributarios, expertos en legislación tributaria. El miedo no se les quita en un foro, en una circular, es irse con un Revisor Fiscal —ejemplo el de la Cámara de Comercio— que tenga credibilidad. (comunicación personal, 2019)

\section{Y otro lo reafirmó:}

Si a uno le llegan de manera concreta, acá hay este proyecto, y usted de manera específica podría vincularse en esto, creo que todos podríamos hacer el esfuerzo, para construir reconciliación. Aquí estamos dispuestos a apuntarle a eso. De esas empresas que pagan renta se podría destinar una parte a Obras por Impuestos. (Mesa, comunicación personal, 2019) 
En noviembre del 2019 emergieron dos grandes referentes que pueden aunar esfuerzos para que la paz territorial se asiente en Risaralda. Primero, la llegada de nuevos gobernantes:

Es importante enamorar, capacitarlos bien, como una oportunidad política, también económica [...]. Si ellos tienen un contratista amigo, que participen, es una invitación pública, que se haga la obra, hay una interventoría, a nosotros nos interesa es ver la obra hecha. (comunicación personal, 2019)

Segundo, el Comité de Cafeteros que está siempre presente y no se rinde, seguramente por su visceral relación con el campo.

Armamos un equipo de ingeniería, fue ejecución directa. Una unidad de ingeniera para ese proyecto: un ingeniero, dibujantes, trabajadora social, todo el equipo se armó. Fue el primer ejercicio que se hizo de contratación de obra, nos fue muy bien. A partir de ese ejercicio, se dijo: "venga metámonos con Obras por Impuestos". Lo que no resultó. Ahora estamos pendientes y los acompańamos también en el tema de Colombia Rural. (Echeverry, 2019)

Y la Cámara de Comercio (de Pereira) que, desde el ejemplo de Apostar (y la familia Franco), potencia el escenario, al poseer una visceral relación con el empresariado ${ }^{3}$ :

Ya se tiene una estrategia para vincular las empresas en los municipios Zomac: se van a convocar a las empresas para mostrarles el modelo. Lo están haciendo con el área de proyectos de la Cámara. La Cámara, como agencia de desarrollo, busca articular municipios-empresa. Municipio: ¿̨usted qué necesidades tiene?, cosas que se pueden hacer con ese recurso y ayudarle al municipio a realizar el proyecto para que pase en planeación.

Llevamos un par de meses (mediados del 2019, mayo-junio). Llegamos tarde a la convocatoria del 2019. Nosotros tenemos que acompañar esos municipios

13 Hay incluso ejemplos de conglomerados nacionales, como Nutresa, que han entendido de tal manera Obras por Impuestos, que han incorporado a su equipo profesionales, cuya única función es esa. 
y que la plata de aquí no se vaya a otros departamentos. La meta es reunir 150 empresas con mayor pago de impuesto de renta. (J. Ramírez, comunicación personal, 2019) $)^{14}$

Las Cámaras de Comercio, más allá de ser entidades con vocación gremial, tienen el potencial de ser agentes de desarrollo regionales que promueven la dinamización de territorios afectados por el conflicto. Este papel, que algunas cámaras asumen con mayor intencionalidad que otras, es altamente significativo en el actual contexto colombiano. El enfoque hacia la promoción del desarrollo regional implica transcender los intereses del sector privado o de algunos actores dentro de este, y alinear las diferentes apuestas y aspiraciones para lograr objetivos comunes con beneficios compartidos entre diferentes grupos de interés en territorios específicos. Este es precisamente el enfoque inclusivo y de participación equitativa que comprende la paz sostenible (Fundación Ideas para la paz y Cámara de Comercio, 2018).

También existen Ideas-fuerza, otra de las alternativas que va más allá de los incentivos económicos y tributarios. La Fundación Ideas para la Paz ha venido insistiendo en que:

El sector empresarial es uno de los llamados a dinamizar y fortalecer los mercados locales de las regiones más afectadas por el conflicto armado. Con los recursos y el conocimiento de la empresa, así como con los incentivos intangibles que este tipo de proyectos que le brindaría a la organización, la empresa puede gestionar programas de empleabilidad, de acceso a mercados o de vinculación de emprendimientos e iniciativas productivas locales a su cadena de valor, particularmente aquellos que resultan de los procesos de reincorporación económica de excombatientes, o de la sustitución de cultivos de uso ilícito. Hay temas ausentes como la promoción de ejercicios de reconciliación que incluyan al sector empresarial en la generación de confianza, la reconstrucción

14 La Cámara de Comercio hoy tiene presencia en todos los municipios de Risaralda (más las cámaras de Dosquebradas y Santa Rosa). Tiene Sede en Apía, vía al Chocó, que fue inaugurada el 30 de junio. Sus sedes son: Santuario, Marsella, Quinchía, Belén de Umbría (atiende Mistrató), Apía (atenderá Pueblo Rico) y La Virginia. Proyecta Empresarios es un corresponsal de la Cámara, en dónde no tiene sede (Santa Cecilia: empresarios). También tiene una Oficina de Municipios que responde a lo que necesitan los empresarios (Ramírez, 2019) 
del tejido social y la exploración de la verdad y la memoria entre diversos actores. (Fundación Ideas para la Paz, 2019)

Posiblemente, el aunamiento de esfuerzos, al lado de los nuevos gobernantes, de los alcaldes, de los gobernadores del periodo 2020-2023, cumpla este sueño:

Hay que generar unos cambios en esas zonas, que las influencias sobre el entorno generen ejemplo y que este se vaya difundiendo, lograr construir la masa crítica, que facilite ese comportamiento colectivo positivo. La empresa ayuda a generar desarrollo, es una retroalimentación. (Ángel Mejía, 2019)

Avanzar, no solo en darle productividad a estos territorios (que no se les ha dado esa oportunidad), sino también generar condiciones de equidad social.

\section{REFERENCIAS}

Agencia de Renovación del Territorio (ART). (2019). Obras por Impuestos. Recuperado de http://www.renovacionterritorio.gov.co/Publicaciones/obras_por_impuestos

Contreras, M. E. (2013). Diversidad de entomofauna acuática en tres ríos de la Eco-región Darién, Chocó biogeográfico (Colombia). Dugesiana, 20(2), 243-250.

Fundación Ideas para la Paz (FIP). (2019). Obras por Impuestos: medida para transformar las zonas más afectadas por el conflicto armado en colombia. Recuperado de http://ideaspaz. org/media/website/FIP_ObrasxImpuestos.pdf

Fundación Ideas para la paz y Cámara de Comercio de Bogotá. (2018). Ecosistema de empresas y paz en Colombia. Recuperado de https://bibliotecadigital.ccb.org.co/ handle/11520/22626

Medicina Legal. (s. f.). Cifras Estadisticas Forensis. Recuperado de http://www.medicinalegal. gov.co/cifras-estadisticas/forensis 
Medina, D. y Martínez, H. (2019). ¿Y dónde están las empresas en la política de paz de Duque? Recuperado de https://lasillavacia.com/silla-llena/red-de-la-paz/-donde-estan-las -empresas-la-politica-de-paz-de-duque-71433

Parra, G. O. (2007). El caldero del diablo: aproximación al pasado y presente de la violencia y la paz en la historia de Quinchia, Colombia, apuntes analiticos: la tierra. Bogotá: Pontificia Universidad Javeriana.

Tuirán, S, A. y Trejos R, L. (2017). Debilidades institucionales en el nivel local. Desafíos de la gestión territorial de la paz. Análisis politico, (90), 77-102.

\section{REFERENCIAS DE LOS TESTIMONIOS}

Ángel Mejía, J. G. (30 de julio de 2019). Actor estatal y privado, local y nacional, desde los años 70. O. Parra, entrevistador.

Certuche, P., y López, D. (16 de octubre de 2019). Gerente y subgerente de Obras y Proyectos SAS. O. Parra, entrevistador.

Corredor, R. (20 de septiembre de 2019). Obispo de la Diocesis de Pereira. O. Parra, entrevistador.

Cortés, J. (26 de julio de 2019 ). Director ejecutivo del Comité Intergremial Risaralda. O. Parra, entrevistador.

Echeverry, J. H. (30 de agosto de 2019). Director ejecutivo del Comité de Cafeteros de Risaralda. O. Parra, entrevistador.

Franco, J. G. (16 de octubre de 2019). CEO Apostar. O. Parra, entrevistador.

García, W. (septiembre de 2019). Contador y revisor fiscal. O. Parra, entrevistador.

Marulanda, I. (9 de octubre de 2019). Senador. O. Parra, entrevistador. Vía WhatsApp. 
Mejía, D. (16 de agosto de 2019). Precandidato a la alcaldía de Mistrató (2020-2024). O. Parra, entrevistador.

Mesa, G. (2 de octubre de 2019). Gerente de Audifarma (la empresa más grande del Eje Cafetero). O. Parra y C. Castaño, entrevistadores.

Nilton, C. y Claros, Y. (10 de mayo de 2019). Gerente de direccionamiento estratégico y líder de planeacion financiera. O. Parra, entrevistador.

Osorio, D. (23 de julio de 2019). Secretaria de Desarrollo Económico y Competitividad de Risaralda. O. Parra, entrevistador.

Pulgarín Montoya, J. I. (2 de septiembre de 2019). Alcalde de Balboa (2016-2019). O. Parra $\mathrm{G}$, entrevistador.

Ramírez, M. L. (19 de julio de 2019). Director, gerente y propietario de El Diario (único diario del departamento). O. Parra, entrevistador.

Ramírez, J. I. (8 de agosto de 2019). Presidente ejecutivo de la Cámara de Comercio de Pereira. O. Parra, entrevistador.

Sánchez, A. (septiembre de 2019). Exgerente general de diversas grandes empresas textileras en Risaralda. O. Parra, entrevistador.

Uribe Flórez, J. A. (2 de septiembre de 2019). Alcalde de Quinchía. O. Parra, entrevistador.

Victorino, H. (9 de julio de 2019). Abogado de la Defensoria del Pueblo en temas indígenas. O. Parra, entrevistador. 